\title{
Depression among Centenarians and the Oldest Old: Contributions of Cognition and Personality
}

\author{
Jennifer Margrett ${ }^{a} \quad$ Peter Martin ${ }^{a} \quad J o h n ~ L$. Woodard $^{b} \quad$ L. Stephen Miller \\ Maurice MacDonald ${ }^{\mathrm{a}}$ Joan Baenziger ${ }^{\mathrm{a}} \quad$ Ilene C. Siegler $^{\mathrm{d}}$ Adam Davey \\ Leonard Poon ${ }^{c}$ for the Georgia Centenarian Study \\ ${ }^{a}$ Iowa State University, Ames, lowa, ${ }^{b}$ Wayne State University, Detroit, Mich., ' University of Georgia, Athens, Ga., and \\ ${ }^{\mathrm{d}}$ Duke University, Durham, N.C., ${ }^{\mathrm{e}}$ Temple University, Philadelphia, Pa., USA
}

\section{Key Words}

Centenarian • Octogenarian · Mental health $\cdot$ Cognition $\cdot$

Personality

\begin{abstract}
Background: An estimated $20 \%$ of adults over the age of 55 experience clinical mental disorders such as depression and anxiety. For older adults, mental health concerns are often undetected, concomitant with physical challenges, and ultimately go untreated. These realities have significant implications for older adults' day-to-day functioning, particularly among the oldest old. Objective: The present study examined the ability of cognition and personality in explaining depression within a sample of octogenarians and centenarians. Methods: Participants were assessed during the most recent cross-sectional data collection of the Georgia Centenarian Study. The final eligible sample included 76 octogenarians (mean: 84.25 years, SD: 2.82; range: $81-90$ ) and 158 centenarians and near centenarians (mean: 99.82 years, SD: 1.72; range: 98-109). Results: Hierarchical regression analyses were conducted to examine the relation between key variables and depressive symptoms in the two age groups. Blocks entered into the analyses included: demographics (i.e. age group, residential status, sex, and ethnicity) and functioning, memory and problem-solving ability, and per-
\end{abstract}

sonality (i.e. extraversion and neuroticism). Models differed for octogenarians and centenarians. Decreased problemsolving ability was related to greater depressive symptoms among octogenarians. For centenarians, institutional residence and increased neurotic tendencies were related to greater depressive symptoms. Conclusion: Study findings demonstrate the need to examine a variety of factors which influence mental health in later life and to consider the unique contexts and differential experiences of octogenarians and centenarians.

Copyright $\odot 2010$ S. Karger AG, Basel

Understanding, assessing, and promoting mental health throughout life are important objectives; however, these aims take on added significance in late life. An estimated $20 \%$ of adults over the age of 55 experience clinical mental disorders such as depression and anxiety [1]. For older adults, mental health concerns are often undetected, concomitant with physical challenges, and ultimately go untreated [1]. These realities have significant

Additional authors include S.M. Jazwinski, R.C. Green, M. Gearing, W.R. Markesbery, M.A. Johnson, J.S. Tenover, W.L. Rodgers, D.B. Hausman, C. Rott, and J. Arnold.

\section{KARGER}

Fax +41613061234

E-Mail karger@karger.ch

www.karger.com (c) 2010 S. Karger AG, Basel

0304-324X/10/0561-0093\$26.00/0

Accessible online at:

www.karger.com/ger
Jennifer A. Margrett, $\mathrm{PhD}$

Department of Human Development and Family Studies

4380 Palmer Building, Room 2354

Ames, IA 50011-4380 (USA)

Tel. +1 515294 3028, Fax +1 515294 2502, E-Mail margrett@iastate.edu 
implications for day-to-day functioning, particularly among the oldest old. Diminished mental health or distress can lead to a decrease in health-promoting behaviors, as well as prohibit treatment of and/or exacerbate other medical conditions $[2,3]$. Most troubling is the fact that older adults proportionately account for more suicides than expected based on population size, with suicide risk being highest among white males aged 85 and older [4]. To better understand mental health outcomes in later life, the current study examined the influence of cognition and personality on depressive symptoms in a unique sample of late life survivors, octogenarians and centenarians.

Mental health in later life is linked to individual differences, particularly indicators of cognition and functioning. As discussed by Boyd et al. [5], cognition is often a key component in explanatory models of depression, and several studies point to a link between cognitive skills and problem-solving ability and mental health in later life [6]. Alexopoulos et al. [7] note that diminished executive functioning in particular may exacerbate geriatric depression and its treatment. The relation between cognition and mental health includes normative cognitive functioning and also extends to non-normative cognitive functioning. For instance, a study by Lee et al. [8] demonstrated a concomitant relationship between mild cognitive impairment and increased depressive symptoms in a sample of older adults. Prior research has found evidence for a relation between later life mental health and indicators of access and functioning, such as ethnicity, residential status, ability to perform activities of daily living, and subjective health $[5,9,10]$.

In addition to cognition and functional indicators, prior work has demonstrated a link between personality traits and mental health. Numerous studies link greater extraversion with positive mental health outcomes such as positive affect, whereas greater neuroticism tends to predict poorer mental health outcomes such as anxiety and negative affect [5]. Neurotic tendencies have been linked to older adults' recovery from depression [11]. In addition to an underlying mechanistic link, personality traits can more practically affect interpretation and reporting of affective and mental health symptoms, including 'over-reporting' by individuals compared to observers [12].

The current literature has not fully addressed the differential experiences of individuals in very late life. Thus, the current study investigated the ability of cognition, personality, and selected demographic and functional indicators in examining depressive symptoms. A second aim was to examine possible differential influences varying between octogenarians and centenarians. Consistent with extant literature, institutional residence, increased neurotic tendencies, and diminished cognitive abilities were expected to account for greater depressive symptoms.

\section{Methods}

\section{Participants}

Participants were part of the most recent Georgia Centenarian Study data collection effort [13]. Due to the study emphasis, centenarians were disproportionately represented. Participants lived in private residences as well as nursing homes and assisted living facilities (see table 1 for sample characteristics). The current analyses utilize self-reported and performance-based assessments. Although participants were not screened for the presence of neurological or psychiatric illness, the current analyses focus on a subset of participants who scored 17 or greater on the Mini-Mental Status Exam (MMSE) [14]. A lower MMSE cutoff was chosen to allow for the increased prevalence of sensory impairment in this late life sample and to include participants who may have mild cognitive impairment [15]. Theoretically, this excluded individuals with likely cognitive impairment and practically for this study ensured that participants were subsequently interviewed on the mental health questions. Selecting from the total sample of 375 participants (88 octogenarians and 287 centenarians), the MMSE inclusion criteria yielded a subsample of 234 adults comprised of 76 octogenarians (mean: 84.25 years, SD: 2.816; range: 81-90) and 158 centenarians and near centenarians (mean: 99.82 years, SD: 1.72; range: 98-109). As noted in table 1 , centenarians and near centenarians were more likely to be female, living in a nursing or personal care home, and widowed.

\section{Measures}

Depressive Symptoms. Depressive symptoms were assessed by the Geriatric Depression Scale (short form) [16] which consists of 15 dichotomous items assessing the presence or absence of depressive symptoms during the past week. Higher scores indicate more depressive symptoms (possible range of $0-15$; observed range of $0-10$ ).

Demographics and Functional Indicators. Sex, residential status, and ethnicity were included in the analyses. Residential status was collapsed to distinguish private and institutional residence (i.e. personal care or nursing home). Perceived difficulty completing desired activities due to health troubles was assessed via a single 3-point Likert item ('not at all' = 2; 'a little or some' = 1; 'a great deal' $=0$ ). Higher scores indicated less perceived difficulty. Interviewers assessed participants' ability to perform activities of daily living (ADLs) via the Direct Assessment of Functional Status [17]. Higher scores indicated better performance. Observed scores ranged from 9 to 81 .

Cognition. Two indicators of cognitive functioning were chosen based on theory and examination of the relation between measures. Given prior work examining dedifferentiation of cognitive abilities in later life [18], it was not surprising that correla- 
Table 1. Age group subsample characteristics and averages on key variables

\begin{tabular}{|c|c|c|c|c|c|c|}
\hline & \multicolumn{4}{|c|}{ Age group } & \multirow{3}{*}{$\chi^{2}$} & \multirow[t]{3}{*}{$\mathrm{p}$} \\
\hline & \multicolumn{2}{|c|}{ octogenarians $(\mathrm{n}=76)$} & \multicolumn{2}{|c|}{ centenarians $(\mathrm{n}=158)$} & & \\
\hline & $\mathrm{n}$ & $\%$ & $\mathrm{n}$ & $\%$ & & \\
\hline Sex: female & 49 & 64.5 & 124 & 78.5 & 5.22 & 0.02 \\
\hline Ethnicity & & & & & 0.01 & ns \\
\hline Caucasian American & 64 & 84.2 & 134 & 84.8 & & \\
\hline African American & 12 & 15.8 & 24 & 15.2 & & \\
\hline Residential status & & & & & & \\
\hline Private home & 65 & 95.6 & 63 & 49.6 & 41.56 & 0.00 \\
\hline Nursing home & 2 & 2.9 & 34 & 26.8 & & \\
\hline Personal care home & 1 & 1.5 & 30 & 23.6 & & \\
\hline Marital status & & & & & 53.87 & 0.00 \\
\hline Currently married & 34 & 44.7 & 10 & 6.3 & & \\
\hline Divorced & 5 & 6.6 & 5 & 3.2 & & \\
\hline Widowed & 36 & 47.4 & 134 & 84.8 & & \\
\hline \multirow[t]{2}{*}{ Never married } & 1 & 1.3 & 9 & 5.7 & & \\
\hline & Mean & $\mathrm{SD}$ & Mean & $\mathrm{SD}$ & $\mathrm{t}$ & $\mathrm{p}$ \\
\hline Depressive Symptoms & 2.01 & 1.98 & 2.51 & 1.87 & -1.84 & 0.07 \\
\hline MMSE & 27.54 & 1.81 & 23.40 & 3.95 & 8.70 & 0.00 \\
\hline DAFS-IADLs & 77.26 & 4.26 & 58.74 & 16.30 & 9.19 & 0.00 \\
\hline Perceived health difficulties ${ }^{\mathrm{a}}$ & 1.20 & 0.75 & 0.98 & 0.73 & 2.10 & 0.04 \\
\hline ILS problem-solving & 36.51 & 3.22 & 28.92 & 7.29 & 8.16 & 0.00 \\
\hline FOME recognition errors & 2.51 & 1.82 & 3.55 & 2.12 & -3.39 & 0.001 \\
\hline Extraversion & 3.23 & 4.06 & 1.91 & 4.21 & 2.11 & 0.04 \\
\hline Neuroticism & -8.12 & 3.96 & -7.32 & 5.39 & -1.08 & ns \\
\hline
\end{tabular}

MMSE = Mini-Mental Status Exam; DAFS-IADLs = Direct Assessment of Functional Status-instrumental activities of daily living; ILS = Independent Living Scales; FOME = Fuld Object Memory Exam.

${ }^{a}$ Higher values represent less perceived difficulty.

tions with this sample of the oldest old revealed that the majority of cognitive measures were highly related $(r=0.50-79)$ including ability specific measures (e.g. verbal fluency) and global assessments of cognitive status. One exception was the Fuld Object Memory Exam recognition memory [19], which demonstrated more modest correlations with the other cognitive assessments $(r=0.25-45)$. Higher scores indicated a greater number of errors and observed scores ranged from 0 to 9 . The second measure was selected due to the theoretical relation between the ability to function in everyday life and mental health. The Independent Living Scales [20] assesses the ability to generate solutions to 20 everyday problems (e.g. what would the respondents do if they 'unexpectedly lost 10 pounds within a month'). Each item was scored on a 3-point scale: inability to perform (0), some difficulty performing (1), or able to perform (2) (possible range $=0$ to 40 ; observed range $=4-40$ ).

Personality. Items from the NEO Five-Factor Inventory, a short form of the revised NEO Personality Inventory [21], gauged personality trait endorsement on a 3 -point scale (i.e. $-1=$ disagree, $0=$ neutral, or $1=$ agree). Given prior research relating extraversion and neuroticism with mental health, we focused on these scales. Observed scores ranged from -11 to 11 on extraversion and -12 to 10 on neuroticism $(\alpha=0.74-0.89)$.

Overall, the two age subsamples differed in several respects. Octogenarians exhibited significantly better instrumental ADL performance, problem solving, and recognition memory, and endorsed more extraverted traits and fewer perceived difficulties due to health.

\section{Results}

Hierarchal regression analysis was employed to compare the ability of cognition, personality, and demographic and functional indicators in explaining depressive symptoms. Analyses were conducted separately by age group. Three blocks of predictors included: demographic and functional variables (i.e. age, residential status, sex, ethnicity, reported impediment due to perceived 
Table 2. Hierarchical regression examining octogenarians' depressive symptoms $(n=58)$

\begin{tabular}{|c|c|c|c|c|c|c|c|c|c|c|c|c|c|}
\hline \multirow{2}{*}{\multicolumn{2}{|c|}{ Model }} & \multicolumn{2}{|c|}{$\begin{array}{l}\text { Unstandardized } \\
\text { coefficients }\end{array}$} & \multicolumn{3}{|c|}{ Standardized coefficients } & \multicolumn{3}{|c|}{ Correlations } & \multicolumn{4}{|c|}{$\begin{array}{l}\text { Model summary and } \\
\text { change statistics }\end{array}$} \\
\hline & & B & SE & $\beta$ & $\mathrm{t}$ & $\mathrm{p}$ & $\begin{array}{l}\text { zero- } \\
\text { order }\end{array}$ & partial & part & $\mathrm{R}^{2}$ & $\begin{array}{l}\text { adj. } \\
\mathrm{R}^{2}\end{array}$ & $\begin{array}{l}\text { SE of } \\
\text { estimate }\end{array}$ & F Chg. \\
\hline \multirow[t]{4}{*}{1} & Constant & 6.43 & 3.29 & & 1.96 & 0.056 & & & & 0.21 & 0.14 & 1.30 & $2.79^{*}$ \\
\hline & Sex & -0.41 & 0.37 & -0.14 & -1.10 & 0.275 & -0.06 & -0.15 & -0.14 & & & & \\
\hline & Residence & -1.20 & 0.99 & -0.16 & -1.21 & 0.233 & -0.26 & -0.17 & -0.15 & & & & \\
\hline & Health difficulties & -0.66 & 0.24 & -0.36 & -2.72 & 0.009 & -0.39 & -0.35 & -0.34 & & & & \\
\hline \multirow[t]{5}{*}{2} & Constant & 9.12 & 3.23 & & 2.83 & 0.007 & & & & 0.38 & 0.29 & 1.18 & $6.76^{* *}$ \\
\hline & Sex & -0.62 & 0.35 & -0.22 & -1.80 & 0.078 & -0.06 & -0.25 & -0.20 & & & & \\
\hline & Residence & -1.14 & 0.90 & -0.15 & -1.27 & 0.211 & -0.26 & -0.18 & -0.14 & & & & \\
\hline & Ethnicity & -0.25 & 0.43 & -0.07 & -0.58 & 0.562 & -0.11 & -0.08 & -0.07 & & & & \\
\hline & $\mathrm{ADL}$ & 0.06 & 0.05 & 0.19 & 1.29 & 0.202 & -0.15 & 0.18 & 0.14 & & & & \\
\hline \multirow[t]{10}{*}{3} & Constant & 9.60 & 3.22 & & 2.98 & 0.005 & & & & 0.42 & 0.31 & 1.17 & 1.6 \\
\hline & Sex & -0.42 & 0.36 & -0.15 & -1.17 & 0.249 & -0.06 & -0.17 & -0.13 & & & & \\
\hline & Residence & -0.78 & 0.91 & -0.10 & -0.85 & 0.398 & -0.26 & -0.12 & -0.09 & & & & \\
\hline & Ethnicity & -0.38 & 0.47 & -0.10 & -0.82 & 0.416 & -0.11 & -0.12 & -0.09 & & & & \\
\hline & $\mathrm{ADL}$ & 0.04 & 0.05 & 0.12 & 0.78 & 0.437 & -0.15 & 0.11 & 0.09 & & & & \\
\hline & Health difficulties & -0.33 & 0.24 & -0.18 & -1.37 & 0.177 & -0.39 & -0.19 & -0.15 & & & & \\
\hline & Problem solving & -0.21 & 0.07 & -0.45 & -2.88 & 0.006 & -0.47 & -0.38 & -0.32 & & & & \\
\hline & FOME errors & -0.07 & 0.10 & -0.09 & -0.76 & 0.452 & -0.04 & -0.11 & -0.08 & & & & \\
\hline & Extraversion & -0.06 & 0.05 & -0.16 & -1.19 & 0.242 & -0.46 & -0.17 & -0.13 & & & & \\
\hline & Neuroticism & 0.06 & 0.05 & 0.14 & 1.09 & 0.279 & 0.23 & 0.16 & 0.12 & & & & \\
\hline
\end{tabular}

FOME $=$ Fuld Object Memory Exam. ${ }^{*} \mathrm{p}<0.05,{ }^{* *} \mathrm{p}<0.01$.

health difficulties, and objective activities of daily living rating), problem-solving ability and recognition memory and personality (i.e. extraversion and neuroticism). Analyses were conducted using SPSS version 15.0 and an $\alpha$ level of 0.05 was adopted. Summaries of the regression analyses are presented in tables 2 and 3 .

The models examining depressive symptoms among octogenarians and centenarians were quite dissimilar. For octogenarians, steps 1 (demographics and functional status) and 2 (cognition) added to the predictive ability of the model. Thus, the accepted model was step 2 , which accounted for $38 \%$ of the explained variance. The only significant individual predictor was the Independent Living Scales, an indicator of problem-solving ability. Among octogenarians, decreased problem-solving ability was related to greater depressive symptomatology. The accepted model examining depressive symptoms among centenarians included steps 1 (demographics and functional status) and 3 (personality), and accounted for $27 \%$ of the explained variance. Significant individual predic- tors included residence (i.e. individuals in nursing or personal care homes reported a greater number of depressive symptoms) and neuroticism (i.e. greater neuroticism was related to greater depressive symptoms).

\section{Discussion}

The current study examined the influence of cognition and personality on depressive symptoms within two subsamples of octogenarians and centenarians. Analyses revealed different predictors across the two age groups, and neither cognition nor personality were consistent across models. For octogenarians, diminished cognitive problem-solving ability emerged as a significant predictor of depressive symptoms. For centenarians, living in a personal care or nursing home and greater neurotic tendencies were indicative of increased depressive symptomatology. Surprisingly, cognition did not emerge as a stronger predictor of depressive symptoms. The utility of 
Table 3. Hierarchical regression examining centenarians' depressive symptoms $(\mathrm{n}=89)$

\begin{tabular}{|c|c|c|c|c|c|c|c|c|c|c|c|c|c|}
\hline \multirow{2}{*}{\multicolumn{2}{|c|}{ Model }} & \multicolumn{2}{|c|}{$\begin{array}{l}\text { Unstandardized } \\
\text { coefficients }\end{array}$} & \multicolumn{3}{|c|}{ Standardized coefficients } & \multicolumn{3}{|c|}{ Correlations } & \multicolumn{4}{|c|}{$\begin{array}{l}\text { Model summary and } \\
\text { change statistics }\end{array}$} \\
\hline & & B & SE & $\beta$ & $\mathrm{t}$ & $\mathrm{p}$ & $\begin{array}{l}\text { zero- } \\
\text { order }\end{array}$ & partial & part & $\mathrm{R}^{2}$ & $\begin{array}{l}\text { adj. } \\
\mathrm{R}^{2}\end{array}$ & $\begin{array}{l}\text { SE of } \\
\text { estimate }\end{array}$ & F Chg. \\
\hline \multirow[t]{4}{*}{1} & Constant & 4.53 & 1.03 & & 4.40 & 0.000 & & & & 0.17 & 0.12 & 1.40 & $3.32^{* *}$ \\
\hline & Sex & -0.06 & 0.50 & -0.01 & -0.12 & 0.905 & 0.09 & -0.01 & -0.01 & & & & \\
\hline & Residence & 0.71 & 0.33 & 0.24 & 2.12 & 0.033 & 0.14 & 0.23 & 0.22 & & & & \\
\hline & Health difficulties & -0.37 & 0.20 & -0.19 & -1.80 & 0.075 & -0.25 & -0.19 & -0.18 & & & & \\
\hline \multirow[t]{5}{*}{2} & Constant & 3.56 & 1.33 & & 2.67 & 0.009 & & & & 0.20 & 0.13 & 1.39 & 1.58 \\
\hline & Sex & 0.06 & 0.50 & 0.01 & 0.12 & 0.901 & 0.09 & 0.01 & 0.01 & & & & \\
\hline & Residence & 0.71 & 0.33 & 0.24 & 2.16 & 0.034 & 0.14 & 0.23 & 0.22 & & & & \\
\hline & Ethnicity & -0.07 & 0.44 & -0.02 & -0.16 & 0.877 & 0.06 & -0.02 & -0.02 & & & & \\
\hline & $\mathrm{ADL}$ & -0.02 & 0.01 & -0.19 & -1.26 & 0.213 & -0.28 & -0.14 & -0.13 & & & & \\
\hline \multirow[t]{10}{*}{3} & Constant & 4.46 & 1.34 & & 3.33 & 0.001 & & & & 0.27 & 0.18 & 1.35 & $3.69^{*}$ \\
\hline & Sex & -0.22 & 0.50 & -0.05 & -0.44 & 0.664 & 0.09 & -0.05 & -0.04 & & & & \\
\hline & Residence & 0.76 & 0.32 & 0.26 & 2.39 & 0.019 & 0.14 & 0.26 & 0.23 & & & & \\
\hline & Ethnicity & -0.16 & 0.44 & -0.04 & -0.37 & 0.713 & 0.06 & -0.04 & -0.04 & & & & \\
\hline & $\mathrm{ADL}$ & -0.02 & 0.01 & -0.23 & -1.56 & 0.123 & -0.28 & -0.17 & -0.15 & & & & \\
\hline & Health difficulties & -0.20 & 0.20 & -0.10 & -0.99 & 0.327 & -0.25 & -0.11 & -0.10 & & & & \\
\hline & Problem solving & -0.01 & 0.03 & -0.04 & -0.26 & 0.800 & -0.24 & -0.03 & -0.03 & & & & \\
\hline & FOME errors & 0.10 & 0.08 & 0.13 & 1.20 & 0.234 & 0.30 & 0.13 & 0.12 & & & & \\
\hline & Extraversion & 0.00 & 0.04 & 0.01 & 0.09 & 0.929 & -0.06 & 0.01 & 0.01 & & & & \\
\hline & Neuroticism & 0.08 & 0.03 & 0.29 & 2.67 & 0.009 & 0.34 & 0.29 & 0.26 & & & & \\
\hline
\end{tabular}

FOME $=$ Fuld Object Memory Exam. ${ }^{*} \mathrm{p}<0.05,{ }^{* *} \mathrm{p}<0.01$.

cognition as a predictor may depend on the specific cognitive ability, skill, or risk factor assessed [22]. One hypothesis is that a threshold effect exists, such that the direct effects of cognition on mental health outcomes are evident only in cases of impairment (e.g. diminished ability to solve daily problems and coping deficiencies). Alternatively, perception of abilities may play a role in indirectly affecting mental health. Specifically, what is the older adult's expectation of change in abilities and at what level should they be for someone of their age and experience? For the octogenarians in our sample, the perception of waning cognitive abilities may have contributed to depressive symptoms. In comparison, for centenarians, the perception and appreciation of maintained abilities may have contributed to a more positive outlook. Finally, there may be a synergistic relationship between cognition and mental health. Diminished mental health could affect cognitive abilities, such as problem-solving ability, which in turn is an important resource in combating issues like depression.
Demographic and functional indicators played a small part in explaining mental health outcomes. The lack of findings related to ethnicity may be due to two factors. For one, the number of African American elders was relatively small. Second, consistent with prior work, residential status may be more explanatory than ethnicity [23]. Also consistent with prior research, institutional status was indicative of increased depressive symptoms for centenarians. Older adults' subjective rating of health impediments and objective ADL ratings played no role above and beyond other predictors. As for the cognitive variables, perhaps distinguishing impaired from nonimpaired individuals would be a more fruitful approach. Additionally, greater attention must be paid to the nature of the data including differences between data sources (e.g. self-report, proxy report, objective assessment). Inclusion of multiple indicators which capture the multidimensionality of constructs, such as health and functioning, would be helpful, although it would be a challenge within a very old sample. Finally, particularly relevant to 
the current discussion of mental health and functioning are the coping mechanisms employed by late life survivors (e.g. type of social comparison and accommodation of goals) and their potential impact on reports of mental and physical health.

When interpreting these findings several points should be considered. First, the current study utilized cross-sectional data. Although more difficult to obtain in samples of the oldest old, longitudinal information is needed. Relevant to the current research questions, longitudinal data (even retrospective or proxy information) could assist in distinguishing early versus late onset of depression. Prior work suggests that such a distinction is important [5]. Longitudinal data could also shed light on the synergistic effects of cognition, personality, and mental health. In particular, theoretical and empirical work is needed to understand the dynamic nature of mental health in later life. Of note is the role of stable attributes and contexts compared to time-varying influences $[24,25]$. Such important individual differences include education, marital status, and life events. An additional challenge for researchers examining behavioral phenomena in very late life is measurement equivalence. As discussed by Baltes and Smith [26], oldest-old adults possess unique charac- teristics distinct from young-old adults and measures of depression and cognition developed for younger individuals may not represent the same constructs when used to assess functioning in a very old sample such as this group of octogenarians and centenarians. The current results highlight the need to examine the unique contexts of later life including the differential experiences and perceptions of octogenarians and centenarians. Such investigations can better inform prevention and intervention efforts.

\section{Acknowledgements}

The Georgia Centenarian Study (Leonard W. Poon, PI) is funded by 1PO1-AG17553 from the National Institute on Aging, a collaboration among The University of Georgia, Tulane University Health Sciences Center, Boston University, University of Kentucky, Emory University, Duke University, Wayne State University, Iowa State University, Temple University, and University of Michigan. Authors acknowledge the valuable recruitment and data acquisition effort from M. Burgess, K. Grier, E. Jackson, E. McCarthy, K. Shaw, L. Strong and S. Reynolds, data acquisition team manager; S. Anderson, E. Cassidy, M. Janke, and J. Savla, data management; M. Poon for project fiscal management.

\section{References}

1 US Department of Health and Human Services: Mental Health: A Report of the Surgeon General - Executive Summary 1999. Rockville, US Department of Health and Human Services, Substance Abuse and Mental Health Services Administration, Center for Mental Health Services, National Institutes of Health, National Institute of Mental Health. http://www.surgeongeneral.gov/ library/mentalhealth/summary.html (accessed September 25, 2007).

$\checkmark 2$ McGuire LC, Strine TW, Okoro CA, Ahluwalia IB, Ford ES: Modifiable characteristics of a healthy lifestyle in U.S. older adults with or without frequent mental distress: 2003 Behavioral Risk Factor Surveillance System. Am J Geriatr Psychiatry 2007;15, 754-761.

3 National Institute of Mental Health: Older adults: depression and suicide facts. http:// www.nimh.nih.gov/health/publications/ older-adults-depression-and-suicide-facts. shtml (accessed December 14, 2007).
4 American Association of Suicidology: Elderly suicide fact sheet 2006. http://www. suicidology.org/associations/1045/files/ Elderly2004.pdf (accessed January 11, 2008).

5 Boyd J, McKiernan F, Waller G: Early-onset and late-onset depression in older adults: psychological perspectives. Rev Clin Gerontol 2000;10:149-159.

-6 Haynie DA, Berg S, Johansson B, Gatz M, Zarit SH: Symptoms of depression in the oldest old: a longitudinal study. J Gerontol Psychol Sci Soc Sci 2001;56:P111-P118.

7 Alexopoulos GS, Kiosses DN, Heo M, Murphy CF, Shanmuhgam B, Gunning-Dixon F: Executive dysfunction and the course of geriatric depression. Biol Psychiatry 2005;58: 204-210.

${ }_{8}$ Lee JS, Potter GC, Wagner HR, WelshBohmer KA, Steffens DC: Persistent mild cognitive impairment in geriatric depression. Int Psychogeriatr 2007;19:125-135.

$\checkmark 9$ Nuyen J, Spreeuwenberg PM, Beekman AT, Groenewegen PP, van den Bos GA, Schellevis FG: Cerebrovascular risk factors and subsequent depression in older general practice patient. J Affect Disord 2007;99:73-81.
10 Anstey KJ, von Sanden C, Sargent-Cox K, Luszcz MA: Prevalence and risk factors for depression in a longitudinal, populationbased study including individuals in the community and residential care. Am J Geriatr Psychiatry 2007;15:497-505.

11 Steunenberg B, Beekman AT, Deeg DJ, Breemer MA, Kerkhof AJ: Mastery and neuroticism predict recovery of depression in later life. Am J Geriatr Psychiatry 2007;15: 234-242.

12 Duberstein PR, Heisel MJ: Personality traits and the reporting of affective disorder symptoms in depressed patients. J Affect Disord 2007;103:165-171.

13 Poon LW, Jazwinski SM, Green RC, Woodard JL, Martin P, Rodgers WL, Johnson MA, Hausman D, Arnold J, Davey A, Batzer MA, Markesbery WR, Gearing M, Siegler IC, Reynolds S, Dai J: Methodological considerations in studying centenarians: lessons learned from the Georgia Centenarian Studies. Annu Rev Gerontol Geriatr 2007;27:231264. 
14 Folstein MF, Folstein SE, McHugh PR: 'Minimental state'. A practical method for grading the cognitive state of patients for the clinician. J Psychiatr Res 1975;12:189-198.

15 Tombaugh TN, McIntyre NJ: The MiniMental Status Examination: a comprehensive review. J Am Geriatr Soc 1992;40:922935.

16 Yesavage JA: Development and validation of a Geriatric Depression Screening Scale: a preliminary report. J Psychiatr Res 1983;17: 37-49.

17 Loewenstein DA, Amigo E, Duara R, Guterman R, Hurwitz D, Berkowitz N, et al: A new scale for the assessment of functional status in Alzheimer's disease and related disorders. J Gerontol 1989;44:114-121.
18 de Frias CM, Lövdén M, Lindenberger U, Nilsson LG: Revisiting the dedifferentiation hypothesis with longitudinal multi-cohort data. Intelligence 2007;35:381-392.

19 Fuld PA: The Fuld Object Memory Test. Chicago, Stoelting Instrument Co., 1981.

20 Loeb PA: Independent Living Scales Manual. San Antonio, Psychological Corp., 1996.

21 Costa PT McCrae RR: NEO Five-Factor Inventory. Port Huron, Sigma Assessment Systems Inc., 1992.

22 Sanders ML, Lyness JM, Eberly S, King DA, Caine ED. Cerebrovascular risk factors, executive dysfunction, and depression in older primary care patients. Am J Geriatr Psychiatry 2006;14:145-152.

23 Harralson TL, White TM, Regenberg AC, Kallan MJ, Have TT, Parmelee PA, Johnson JC: Similarities and differences in depression among black and white nursing home residents. Am J Geriatr Psychiatry 2002;10:175184.
24 Choi NG, Bohman TM: Predicting the changes in depressive symptomatology in later life: how much do changes in health status, marital and caregiving status, work and volunteering, and health-related behaviors contribute? J Aging Health 2007;19:152177.

25 Martin P, Martin M: Proximal and distal influences on development: the model of developmental adaptation. Dev Rev 2002;22:7896.

26 Baltes PB, Smith J: New frontiers in the future of aging: from successful aging of the young old to the dilemmas of the fourth age. Gerontology 2003;49:123-135. 